\title{
LA FUERZA DE LA DEBILIDAD DIONISÍACA
}

\author{
Michel MafFesoli \\ Miembro del Instituto Universitario de Francia
}

olamente se comprende lo que sucede si se sabe captar lo inau-
gural. Es por esto que todo pensamiento auténtico retoma
una especificidad de la existencia humana: se siembra para
cosechar más tarde.

Es así como a finales de los años setenta anuncié el retorno de Dionisios, dios de la orgía, insistiendo en el papel, cada vez más importante, que la pasión (orge) iba a tener en nuestras sociedades. De la misma manera, en relación con otro sentido de la palabra (orgos: iniciado), señalaba el lugar primordial que la iniciación iba a asumir en el neotribalismo contemporáneo. ¿Qué habría que decir, sino que al contrario de lo que se acostumbra decir hay energía en la vida social? Pero hay que reconocer, aunque esto les choque a muchos observadores, que esta energía se expresa a la vez en lo inmediato, en lo cercano, en lo cotidiano, en la búsqueda de un hedonismo refinado. En todo caso, por fuera de las instituciones racionales, terreno predilecto de una sociología miope.

Es así como se oye con frecuencia hablar de hiperconsumo. Una más de las exageraciones utilizadas para ocultar el hecho de que ya pasamos a otra cosa.

Para quien no esté dopado por el conformismo reinante, es evidente que el desmesurado apetito por los objetos, la rápida obsolescencia de los amores, el frenesí que genera lo nuevo, deberían incitarnos a darle otro nombre al mariposeo vertiginoso que caracteriza las maneras de ser posmodernas. Georges Bataille, con su noción de gasto, había proféticamente esbozado sus límites. Pero hoy en día, el consumo, la sed intensa de derroche a todo nivel, se volvió una realidad cotidiana que está en las antípodas de la mitología del progreso característica de la modernidad.

$\mathrm{Y}$ es justamente con la invención de un mito, el mito del Progreso, que tanto Auguste Comte como Saint-Simon pretendían luchar contra el oscurantismo que ellos les atribuían en 
un principio a los diversos politeísmos y posteriormente a los monoteísmos semíticos.

Todo esto hace pensar en la religión industrial de Saint-Simon, que - ¿lo tenemos suficientemente claro? - debía fortalecer el todo-productivismo moderno, su gran ideología del crecimiento. Y la sociedad de la producción, tal como se implantó a lo largo del siglo xIx y a principios del xx, tenía que desembocar necesariamente en esta sociedad de consumo que analizó tan apropiadamente Jean Baudrillard, quien veía precisamente en ella, en uno de sus libros menos conocidos pero particularmente impactante, el espejo de la producción.

Toda mitología necesita términos que funcionen como oscilógrafos, que le sirvan de cursores. Estos términos constituyen una especie de caja de resonancia en la que cada quien, así sea de manera inconsciente, puede reconocerse fácilmente. La trilogía Progreso, Producción, Consumo tuvo exactamente esa función. Esas palabras-clave hacían eco a las preocupaciones populares y son fundadoras de la mitología moderna. Pero se volvieron pura salmodia, es decir, términos que nos continúan repitiendo en los discursos oficiales. Que se recitan religiosamente en toda ocasión. Que hacen parte de la opinión común, de la retórica de rutina. Pero a los cuales justamente por esa razón ya no se les presta atención. iYa desde hace rato se sabe: letanía, liturgia, letargo!

Numerosos son, en efecto, los índices que contradicen el amodorramiento de la sociedad instituida y que se oponen a discursos o análisis a propósito para servirles de legitimación y de racionalización.

Sucede con frecuencia que un valor en el ocaso, agonizante, experimente una súbita recuperación, lo que nos recuerda el legendario canto del cisne que muriendo transforma su grito ronco en lánguida pero inútil melodía. Y es así como pueden entenderse la diversidad de discursitos sobre el valor del trabajo, iy otras lamentaciones sobre la tasa de crecimiento o sobre la famosa capacidad adquisitiva! Y debido a que nadie les pone atención, más insistentes se hacen. iComo si en últimas la vida se resumiera en la preocupación por suscribir un plan de ahorro para adquirir vivienda! En realidad, la pretendida crisis económica (PEC) no tiene otro origen. Es, ante todo, crisis de civilización. Es, apegada a su etimología (krisis), un juicio que se le hace a lo 
que se acaba. iJuicio que los valores dionisíacos lanzan contra la prevalencia prometeica del todo económico!

Flota un olor a quemado en el aire del tiempo. Y, de diversas maneras, se trata de la sed intensa de derroche a todo nivel o, lo que es lo mismo, de empeñarse en que para ganar la vida no haya que perderla. He ahí por qué una mitología del consumo tiende a ocupar el sitio del mito algo ajado y desgastado de la dupla producción-consumo.

Se alcanza el paroxismo, evidentemente, con las decenas de miles de vehículos que son quemados cada año dentro del perímetro urbano de las grandes ciudades francesas. ¿Será necesario precisar que estamos ante un símbolo elocuente? $\mathrm{O}$ al menos muy instructivo si se tiene en cuenta hasta qué punto el automóvil fue el signo absoluto de la que se llamó sociedad de consumo. Objeto costoso, es a la vez producto de una vida de trabajo y lo que permite, igualmente, ir a ese trabajo. Es, al mismo tiempo, aquello gracias a lo cual uno puede escapar, real o fantasmáticamente, de la obligación de trabajar. Finalmente, este "objeto-signo" es la suma de una inversión libidinal de la que se han ocupado ampliamente los psicoanalistas.

iEs el objeto el que arde!

Anotemos, por otra parte, que no es el automóvil del rico, bien protegido en su garaje vigilado, el que arde. No, es el que se encuentra en la calle. Al lado de un edificio en la ciudad, en lo que los medios llaman ahora los "barrios". Puede en consecuencia pertenecer este automóvil a alguien conocido o de la familia.

El hecho de consumir por el fuego tal objeto no es un acto político como frecuentemente se lee en los análisis. Constituye más bien una postura lúdica. Una antigua estructura antropológica que sitúa la destrucción en el corazón mismo de la construcción. Como lo dice el adagio romano: pars destruens, pars construens. La construcción por la destrucción, de alguna manera. Y tengamos en cuenta también que hay en esos incendios curiosas reminiscencias de los festivales estudiantiles: iBerkeley en 1964 o rue Gay-Lussac en 1968! De ahí proviene esa opinión convencional en la que un petainismo ${ }^{1}$ inconsciente se

1 Relativo al mariscal Pétain, jefe del Estado francés (1940-1944), que colaboró con los nazis (nota del traductor). asocia a un cretinismo ortodoxo para clamar que hay a la vez que “trabajar más y olvidar mayo del 68”. Los múltiples mantras 
a propósito de trabajo, familia, patria son actualmente moneda corriente entre la intelligentsia francesa.

En El combate con el demonio Stephan Zweig habla, a propósito de Nietzsche o de Hölderlin, de un demonismo que anima sus obras y su vida. ¿Sería atrevido decir que, en ciertas épocas, tal demonismo permea la sociedad en su conjunto? ¿Que La sombra de Dionisios se extiende sobre las megápolis posmodernas?

Lo que aparece como paroxístico en la literatura se expresa en tonalidad menor en el conjunto de los objetos de consumo de la vida cotidiana. En efecto, ya no son pensados ni construidos para durar. Se inscriben en la ronda de lo que se concibe bajo la égida de la precariedad. Objetos, situaciones, relaciones marcadas con el sello de la obsolescencia programada. Esta se vive igualmente en el campo de los afectos. Ya no se asocia amor con "para siempre". Desgaste, fatiga, costumbre, todo hace que, en general, las relaciones de amistad o las amorosas no se inscriban ya en la larga duración. iY ya sabemos en qué estado está la institución conyugal que busca paliar su fragilidad proponiéndoles matrimonio a los homosexuales y a otras orientaciones sexuales heterodoxas! iHay que encontrarles trabajo a los curas y al resto de la fauna de repartidores de bendiciones!

La teoría tampoco es lo que era. Los conceptos hacen agua por todas partes, los dogmas ya no encuentran clientela. El universalismo solo convence a algunos fanáticos de la Razón, de la Ciencia, del Progreso, o de otras iglesias de la misma laya.

La moda favorece las verdades parciales, momentáneas, o incluso las aproximativas. Pero tal relativismo, al insistir en el instante, favorece la creación. Ciertamente, la energía individual o colectiva ya no es movilizada al servicio de la larga duración. Al estar focalizada en el instante, la intensidad con que se vive se acrecienta.

Esto es exactamente lo que expresa la sociedad de consumo. Otra mitología, que ya no reposa en la religión industrial de una economía individual y del mundo, sino más bien en el gasto, la pérdida. Una inconsciente inconciencia que sabe, por sabiduría ancestral, que a veces quien pierde, gana. Después de todo ipor qué no apostarle a la posibilidad de que se encuentren en el consumo, ese lujo nocturno de la imaginación, las premisas de una intensa y fecunda creación? Es decir de una verdad societal. Ya lo decía Goethe: "Solamente lo que es fecundo, es verdad". 
iHacer de la propia vida una obra de arte! Poner todas las cosas y a todos en la plaza pública hace parte de esa estetización de la existencia en la que lo que importa es ante todo experimentar pasiones y emociones comunes. Desde este punto de vista, la estética juega el papel de cemento ético. Mientras que en las sociedades tradicionales el arte era un elemento de la vida de todos los días, progresivamente ha sido momificado. Marginalizados, separados de lo cotidiano, la creación, la creatividad, el juego, la imaginación, contaminan de nuevo la existencia del hombre sin cualidades. Nietzsche murió loco por haberlo intuido en un momento inoportuno. Y resulta que de la burguesía bohemia a la chusma, del intelectual esteta al deportista preocupado por su cuerpo, del nómada de zonas semiurbanas al ecologista obsesionado por las legumbres macrobióticas, hay una preocupación por la creatividad vivida en el día al día. El arte permea todo lo que hasta entonces se consideraba anodino.

Cada época tiene sus imágenes y sus propios mitos. Pero ellos lo único que hacen es retomar y actualizar potencialidades arcaicas que se creían superadas y que de un momento a otro recuperan una sorprendente juventud.

Pero esto no es tan fácil de admitir debido a la idea fuertemente arraigada de un Progreso de la humanidad, de un desarrollo garantizado por una Historia y que tiene un objetivo remoto que alcanzar. Con sus matices judíos, cristianos, musulmanes, la ideología semita insistió en un desarrollo histórico con una característica esencial: la de ser lineal. Completamente distinto es el enfoque griego o el de las diversas concepciones orientales que reposan en el retorno cíclico de las cosas. De donde procede la importancia concedida a los tiempos míticos que privilegiaban la experiencia.

$\mathrm{Al}$ respecto, podemos remitirnos a un ilustrativo pasaje de La ciudad de Dios (xII, 14,1) en el que San Agustín censura con firmeza a los "sabios de este mundo que creyeron deber introducir una marcha circular del tiempo para renovar la naturaleza". El mito, en efecto, remite al renacimiento periódico de toda cosa. Círculo, o espiral, porque las cosas no regresan exactamente al mismo nivel. Es así como la sociedad del trabajo está cediéndole el lugar a la de la creación.

Que estamos viviendo una época de grandes cambios es cosa actualmente admitida. De manera latente o explosiva, el derrumbe 
de los grandes valores sobre los que reposaba la solidez de la vida social es una evidencia. Pero será con muchas reticencias como se aceptarán las consecuencias psicológicas y sociales. Tan es así, que la renovación de ciertos mitos aterra a ciertos intelectuales (políticos, científicos, periodistas) que tienen como función la gestión de mitos que de ninguna manera desean considerar saturados.

En época de cataclismos, nada ni nadie escapa al efecto de los diversos tsunamis que la actualidad presenta profusamente. Un ejemplo es el que sumerge el zócalo fundador de la modernidad: el trabajo.

Para retomar una conocida expresión del filósofo Immanuel Kant, tenemos ahí, claramente, el imperativo categórico mayor. El que preside la realización personal y la del mundo. Es por lo que se elabora la mitología del esfuerzo que inaugura la prevalencia del trabajo, del productivismo y de la economía que es su consecuencia. Pero el hecho mismo de que este valor sea reciente no nos autoriza a considerarlo como eterno. En efecto, son numerosos los indicios que empíricamente lo señalan como saturado. Lo que obliga a observar que pueden existir otras maneras de afectar el entorno social y natural.

Pero como ya lo señalé, todo lo que acaba entona su canto del cisne: el último antes de morir. Y, así no sea más que para abrir un paréntesis, es curioso señalar cómo la expresión valor trabajo constituye el zócalo imposible de obviar de las diversas cantaletas sociopolíticas. Valor trabajo que, si recordamos bien, era justamente el elemento clave de la suma teológica de Karl Marx: iEl capital! ¿Revancha del marxismo? En todo caso, según una intelectualidad en el colmo del desfase, es con la revalorización del trabajo que se va a revolucionar, conservar, cambiar y reformar la sociedad. ¿Y si el problema ya no estuviera ahí? ¿Si este hechizo no fuera, al fin de cuentas, más que una corta desaceleración del ocaso de la modernidad?

En efecto, de diversas maneras, en particular para esas jóvenes generaciones que ya son la sociedad del mañana, es claro que lo esencial de la existencia no consiste en perder la vida para ganarla. El imperativo debes cede progresivamente el lugar al optativo toca. Ciertamente, es necesario trabajar. Pero esto solamente constituye un elemento entre otros. Un simple aspecto, no necesariamente el más importante, de las inversiones personales. 
La mitología del bienestar, la del hedonismo latente hace que, simultáneamente, se pueda ser un gerente y tener múltiples centros de interés y que cada uno tenga su propia importancia. Hobbies múltiples, actividades como aficionado en diversas artes, trabajo en interinidad, turn over de los ejecutivos, interés por la estética en las oficinas, heliotropismo que valoriza las regiones de clima temperado, incluso, concediéndoles una revancha a sus valores, todo vale en el esfuerzo para relativizar los aspectos incómodos del trabajo.

En consecuencia, las condiciones de vida, en el tiempo reservado al trabajo, ya se tienen en cuenta. Resumiendo, lo cualitativo está de moda. Todas estas prácticas cotidianas, poco teorizadas pero ampliamente vividas nos recuerdan que hay civilizaciones, y no necesariamente las menos importantes, en las que la creación tiende a prevalecer.

\section{Prometeo le cede el lugar a Dionisios}

[n esta perspectiva ¿qué es la creación si no la capacidad de movilizar parámetros humanos tales como lo lúdico, lo onírico, Lel imaginario colectivo? El Renacimiento fue uno de esos momentos en los que banqueros, empresarios, artistas y aventureros de todo tipo pensaban la vida social como un todo. Y actuaban en consecuencia. Es algo de ese orden que se expresa en los mitos "holísticos" de la posmodernidad naciente.

Metrosexuales y todo el espectro de las clases medias antiglobalización, adeptas al decrecimiento y al pacto ecológico, se esfuerzan, de diversas maneras, por relegar a un segundo plano la prevalencia del trabajo. En alguna medida gracias a la globalización, lo propio de la mitología posmoderna es insistir en la sinergia existente entre el placer arcaico del bienestar y el desarrollo tecnológico. Y cuando se sabe que más de la mitad del tráfico en las redes de Internet está relacionado con encuentros amistosos, eróticos, filosóficos o religiosos, se entiende claramente en qué consiste esa relativización del valor trabajo. Es esta relativización la que pone en evidencia el retorno de la creatividad en la vida social.

El campo abierto por una tal transmutación de los valores es inmenso. Falta explorarlo. En una palabra, y es esto lo que va a 
encontrarse en todos los mitos que hacen hincapié en la vida, la experiencia, la realización personal, etc., es que no hay real competencia sino en función de una determinada apetencia. Resumiendo: no se puede movilizar la energía, individual o colectiva, si no se está en sintonía con el inconsciente de la época. En este caso, serán prospectivos, es decir estarán en sintonía con un futuro cercano, los que sepan apostarles a esos valores presentes en el imaginario del momento y que un racionalismo estrecho había relegado a la prehistoria. El ego cogito, fundamento de la modernidad, está progresivamente cediéndole el lugar a un ego affectus est. Afectado por los otros, por lo sagrado, por la naturaleza, por los humores (personales, colectivos). Es esto lo que conviene pensar: la mutación de una existencia dominada por el materialismo moderno, es decir ya anticuada, hacia otra manera de estar-juntos en donde lo inmaterial vuelve a encontrar fuerza y vigor.

Se trata de valores inmateriales que están en plena vigencia en la vida política, social y económica. Y no carece de interés el que las jóvenes generaciones sean las protagonistas de esta nueva mirada a la naturaleza y a la sociedad. Es por la misma razón por la que en su actitud algo irreverente, los "creativos" multiformes son hombres de su tiempo reeditando la eterna juventud del mundo. Es eso lo que se cristaliza en la figura emblemática de Dionisios, ila del puer aeternus! 